$$
\text { DOE/PC/92534-6 }
$$

\title{
SELECTIVE CATALYTIC REDUCTION OF SULFUR DIOXIDE TO ELEMENTAL SULFUR
}

Quarterly Technical Progress Report No. 6

October - December 1993

\author{
Wei Liu \\ Maria Flytzani-Stephanopoulos \\ Adel F. Sarofim
}

Department of Chemical Engineering

Massachusetts Institute of Technology

Cambridge, MA 02139

Prepared for

The U.S. Department of Energy

The Pittsburgh Energy Technology Center

Pittsburgh, Pennsylvania

Technical Project Officer: Dr. Richard Tischer

Grant No.: DE-FG22-92PC92534

US/DOE Patent Clearance is not required prior to the publication of this document
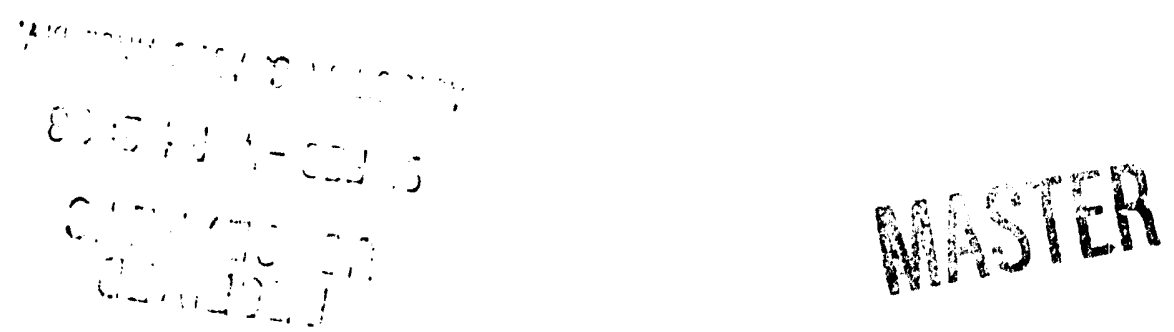


\section{- UNIVERSITY CONTRACTOR, GRANTEE, AND COOPERATIVE AGREEMENT RECOMMENDATIONS FOR ANNOUNCEMENT AND DISTRIBUTION OF DOCUMENTS}

(See Ir.strucions on Reverse Side)

\begin{tabular}{l|l|l|}
\hline 1. DOE Repor No. & 2. DoE Contract No. & 3. DOE Funding OHice \\
DOE/PC/92534-6 OSTI UC Calegory No & DOE/PETC \\
\hline
\end{tabular}

5. Title

Selective Catalytic Reduction of Sulfur Dioxide to Elemental Sulfur

6. Type of Document (" $x$ " one). Two completely legible reproducible copies should be transmitted.
a. Scientific and technical report: I monthly
quarterly
ᄀ annual ᄀ final
.7 topical
ᄀ other
b. Conterence paper: Name of conference (no abbreviations)

Location (city/st/ctry)

Date (moiday/yr) Sponsor

Contents: ב proceedings

ป viewgraphs

ᄀ paper

I poster sessions

c. Computer Media:

Document is accompanied by $I$ magnetic tape(s)

I diskette(s)

ב other (specity)

d. Other (e.g.. journal anticle, manuscript, manual, etc.) (specity)

\section{Patent Information}

a. Does this intormation product disclose any new equipment, process, or material? No J Yes if so, identify page nos.

b. Has an invention disclosure been submitted to DOE covering any aspect of this information product? $\mathbb{X}$ No $\neg$ Yes If so. identify the DOE (or other) disclosure number and to whom the disclosure was submitted.

c. Are there any patent-related objections to the release of this information product? $\gtrsim$ No $\neg$ Yes lf so, sta:e these objections

d. Does inis material contain Proprietary information? No I Yes

8. Additional information, remarks, and special handling instructions. (Continue on separate sheet, if necessary.)

\begin{tabular}{l} 
9. Submitted by (Name and Position) (Please print or type) \\
Dr. Maria F1ytzani-Stephanopoulos \\
Visiting Professor of Chemical Engineering \\
\hline $\begin{array}{l}\text { Organization } \\
\text { Massachusetts Institute of Technology }\end{array}$
\end{tabular}




\begin{abstract}
Elemental sulfur recovery from $\mathrm{SO}_{2}$-containing gas stream is highly attractive as it produces a salable product and no waste to dispose of. However, commercially available schemes are complex and involve multi-stage reactors, such as, most notably in the Resox (reduction of $\mathrm{SO}_{2}$ with coke) and Claus plant(reaction of $\mathrm{SO}_{2}$ with $\mathrm{H}_{2} \mathrm{~S}$ over catalyst). This project will investigate a cerium oxide catalyst for the single stage selective reduction of $\mathrm{SO}_{2}$ to elemental sulfur by a reductant, such as carbon monoxide. Cerium oxide has been identified in recent work at MIT as a superior catalyst for $\mathrm{SO}_{2}$ reduction by $\mathrm{CO}$ to elemental sulfur because its high activity and high selectivity to sulfur over COS over a $w_{1}$ de temperature range $\left(400-650^{\circ} \mathrm{C}\right)$. The detailed kinetic and parametric studies of $\mathrm{SO}_{2}$ reduction planned in this work over various $\mathrm{CeO}_{2}$ formulations will provide the necessary basis for development of a very simplified process, namely that of a single-stage elemental sulfur recovery scheme from variable concentration gas streams, The potential cost- and energy-efficiency benefits from this approach can not be overstated. A first apparent application is treatment of a regenerator off-gases in power plants using regenerative flue gas desulfurization. Such a simple catalytic converter may offer the long-sought "Claus-alternative" for coal-fired power plant applications.
\end{abstract}




\section{PROGRESS SUMMARY}

Last quarter we reported that transition metal-doped fluorite oxides are active catalysts for sulfur dioxide reduction. Systematic examination of the $\mathrm{Ce}$ $\mathrm{Cu}-\mathrm{O}$ catalyst system identified the catalyst containing about 15 at $\%$ copper as the most active and stable. In this quarter the $\mathrm{Cu}-\mathrm{Ce}-\mathrm{O}$ catalyst was characterized by several analytical techniques to understand the relationship between catalytic properties and catalyst structure and composition.

\section{X-ray Powder Diffraction(XRD) Analysis}

XRD was performed on a Rigaku RU300 X-ray diffractometer using $\mathrm{Cu} \mathrm{K}$ $\alpha$ radiation. The X-ray tube was operated at $200 \mathrm{~mA}$ and $50 \mathrm{kV}$. A diverging slit of 10 , scattering slit of 10 , and receiving slit $0.15^{\circ}$ were used. In the XRD phase compesitiors survey, a scan rate of $10 \% / \mathrm{min}$ was used while in the lattice parameter measurement $1 \%$ min was used. XRD analyses of the $\mathrm{Cu}-\mathrm{Ce}-\mathrm{O}$ system identified two crystal phases, fluorite-type and copper oxide, in catalysts containing over 20 at\% copper, and only the fluorite structure in the composites containing less than 20 at $\% \mathrm{Cu}$. Also in the Y-doped and $\mathrm{Cu}$ doped zirconia catalysts, only the fluorite-type structure was found. Two small peaks due to $\mathrm{CuO}$ phase were found in the fresh $3.7 \mathrm{at} \% \mathrm{Cu} / \mathrm{CeO}_{2}$ catalysts as shown in Figure 1, but, these two peaks disappeared after use in reduction of sulfur dioxide. The distinct fluorite-type diffraction pattern was found in both the used and fresh $\mathrm{Cu}-\mathrm{Ce}-\mathrm{O}$ catalysts, which indicates that the fluorite oxide was stable in the present reaction conditions.

Figure 2 shows the variance of lattice space with copper content in the $\mathrm{Cu}_{\mathrm{x}} \mathrm{Ce}_{1-\mathrm{x}}(\mathrm{La}) \mathrm{O}_{2-\mathrm{x}}$. The lattice parameter of ceria FCC crystal structure was calculated with standard formula $2 D_{h k l} \sin \theta=n \lambda(\lambda=0.15405 \mathrm{~nm}$ for $\mathrm{CuK} K \mathrm{l})$ using the (111) diffraction line which is the strongest line and also contains the 
least interference from $\mathrm{Cu} \mathrm{K} \alpha 2$ radiation. The data plotted in Figure 2 can be roughly correlated with a linear equation which suggests the formation of a solid solution according to Vegard's rule. The lattice parameters for both fresh and used $x=0.15$ catalysts strongly deviate from the straight line. The unit cell of the $x=0.15$ sample is equal to the $\mathrm{Ce}(\mathrm{La}) \mathrm{O}_{2}$, suggesting no solid solution formation. The fact that the $x=0.15$ catalyst was identified as the most active catalyst then suggests that solid solution formation may not improve the catalytic activity. The stability of the solid solution $\mathrm{Cu}-\mathrm{Ce}-\mathrm{O}$ was tested by calcining $\mathrm{x}=0.15$ and 0.25 samples for 17 hours at $7500^{\circ} \mathrm{C}$ in air. Relatively small $\mathrm{CuO}$ peaks were found in the XRD diagrams of both catalysts. As shown in Figure 2, their lattice parameters were also changed to a same value. It seems that a solubility limit was reached.

\section{Scanning Transmission Electron Microscopy(STEM) Analysis}

STEM analyses were performed on a Vacuum Generators HB-5 and HB603 apparatus which provides high spatial resolution for both imaging and compositional analysis. To do this experiment, finely grounded catalyst powder was embedded in a resin matrix. Then, the matrix was ultramicrotomed to slices of 80 to $120 \mathrm{~nm}$. STEM analyses of the fresh $\mathrm{Cu}$ Ce-O composite catalyst found the copper as small particles(a few nm) and large agglomerates $(>10 \mathrm{~nm})$, the latter increasing in population with the copper content. Figure 3 is the elemental map on a used $x=0.2$ catalyst. Extensive copper coverage and association with sulfur was observed. The copper particle size varies from a few to a few hundred nanometer. In contrast, a higher number and uniform dispersion of small copper particles(a few $n$ m) was found on the used $x=0.15$ catalyst as shown in Figure 4 . This may explain why the $x=0.15$ catalyst was much more active than the $x=0.2$ though there is not much difference in elemental composition. Figure 5 shows 
the elemental mapping for the $\mathrm{Cu} / \mathrm{CeO}_{2}$ before and after use. In Figure 5, the left-hand-side top and bottom pictures are the dark field images of the fresh catalyst matrix and the bright field image of the used one, respectively, while the right-hand-side pictures are the corresponding elemental mapping images. The rulers are applied to the elemental maps. Many large copper particles $(-300 \mathrm{~nm})$ were found in the fresh catalyst, but relatively smaller particles on the used one. Sulfur found on the used catalyst was also associated with copper. It is interesting that the copper became more finely dispersed in the used catalyst. This result confirms the $\mathrm{CuO}$ peak disappearance in the XRD diagram of the used $\mathrm{Cu} / \mathrm{CeO}_{2}$ catalyst.

\section{X-ray Photoelectron Spectroscopy(XPS) Analysis}

XPS analysis on the catalyst surface was performed on a Perkin Elmer 5100 Model instrument equipped with a Argon ion gun. Mg X-ray source of $1253.6 \mathrm{eV}$ was used with the power set at $15 \mathrm{kV}$ and $300 \mathrm{~W}$. Catalyst powder sample was pressed on a indium plate and transferred to the vacuum chamber without any pretreatment. Data was acquired under vacuum about 10-9 torr. Figure 6 shows the XPS survey of the fresh $\mathrm{x}=0.15$ catalyst. Comparison with the standard spectra[1] finds the $\mathrm{Cu}_{2 p}$ satellite similar to the reduced copper $\left(\mathrm{Cu}, \mathrm{Cu}^{+1}\right)$ and $\mathrm{Ce}_{3 \mathrm{~d}}$ satellite for both fresh and used catalysts similar to bulk ceria. In other experiments, the $\mathrm{Cu}_{2 p} \mathrm{XPS}$ of the $\mathrm{CuO} / \gamma-\mathrm{Al}_{2} \mathrm{O}_{3}$ looked exactly like that of $\mathrm{CuO}$, but, the $\mathrm{Cu}_{2 p}$ XPS of the $\mathrm{CuOx} / \mathrm{CeO}_{2}$ is between the $\mathrm{CuO}$ and reduced $\mathrm{CuO}\left(\mathrm{Cu}, \mathrm{Cu}^{+1}\right)$. The binding energies of the $\mathrm{Cu}_{0.15} \mathrm{Ce}_{0.85}(\mathrm{La}) \mathrm{O}_{\mathrm{x}}$ catalyst found by using ESCA MULTPLEX with total 90 min acquisition time are summarized in Table 1. Hydrocarbon-type carbon peak was found in all the samples which may be inadvertently contaminated Thus, all the binding energies were corrected by referring to $\mathrm{Cls}$ peak at 284.6 $\mathrm{eV}$, which contaminated the sample inadvertely. The $\mathrm{Cu}_{2 \mathrm{p} 3 / 2}$ binding 
energy $(932.7 \mathrm{eV})$ of fresh catalyst confirmed the reduced copper state. $\mathrm{CuO}$ also distinguishes itself from $\mathrm{Cu}_{2} \mathrm{O}$ and $\mathrm{Cu}$ by having a shake-up peak. However, it is difficult to differentiate the oxidation sate of copper in sulfide species. The $\mathrm{Ce}_{3 \mathrm{~d} 5 / 2}$ binding energies of both fresh and used catalysts are consistent with literature data for $\mathrm{CeO}_{2}$. Two $\mathrm{O}_{1}$ s peaks were found in the XPS of the used catalyst while only the peak at lower binding energy was found on the fresh one. The peak of higher binding energy can be assigned to sulfate or carbonate, while the peak of low binding energy is assigned to metal oxide. Similarly, double $S_{2 p}$ XPS peaks were found on the used catalyst. The metal sulfate and sulfide contribute to the high and low binding energies, respectively. The sulfide peak is a major peak.

The quantitative surface compositional analysis of the $\mathrm{Cu}_{0.15} \mathrm{Ce}_{0.85}(\mathrm{La}) \mathrm{O}_{\mathrm{X}}$ catalyst by XPS is given in Table 2 . The results indicate that the surface was enriched in copper after use. The $\mathrm{Cu} / \mathrm{Ce}$ and $\mathrm{S} / \mathrm{Cu}$ ratios decreased by sputtering the surface with argon ion. But, the $\mathrm{S} / \mathrm{Cu}$ ratio did not reach a zero value, which is considered to be due to the interference from the catalyst pores rather than sulfur diffusion in the bulk.

\section{Réaction Mechanism}

Previous studies have suggested that the reduction of sulfur dioxide by carbon monoxide on ceria proceeds via a redox mechanism[2].

$$
\begin{aligned}
& \text { Cat-O }+\mathrm{CO} \rightarrow \text { Cat- }\left[\text { ] }+\mathrm{CO}_{2}\right. \\
& \text { Cat- }[]+\mathrm{SO}_{2} \rightarrow \text { Cat-O }+\mathrm{SO} \\
& \text { Cat- }[\text { ] }+\mathrm{SO} \rightarrow \text { Cat-O }+\mathrm{S}
\end{aligned}
$$

Creation of oxygen vacancies on the surface is a key step. The introduction of transition metals may provide surface sites for $\mathrm{CO}$ adsorption and facilitate the reduction of the fluorite oxide surface through strong metal-suppor interaction as found in the $\mathrm{Pt}-\mathrm{CeO}_{2}[3]$ system. 


$$
\begin{aligned}
& \text { Cat-M---CO + Cat-O } \rightarrow \text { Cat-M + Cat-[ ] + } \mathrm{CO}_{2} \\
& \text { Cat-M }+\mathrm{S}_{\mathrm{X}} \rightarrow \text { Cat-MS } \\
& \text { Cat-MS } \\
& \text { C CO } \rightarrow \text { Cat-M + COS }
\end{aligned}
$$

However, the transition metal can be sulfided by the elemental sulfur product through reaction 5 . Thus, the adsorbed $\mathrm{CO}$ on catalyst surface can pick up oxygen(reaction 1) and sulfur(reaction 6). COS formation thus becomes the result of these two competitive processes. COS formation prevails in following two cases. When excess $\mathrm{CO}$ exists or the oxidant is not sufficient, the extra $\mathrm{CO}$ reacts with elemental sulfur to form COS. When the oxygen is more strongly bound than sulfur, the adsorbed $\mathrm{CO}$ picks up sulfur to form COS. This reasoning is evidenced by the COS evolution profiles(Figure 7 and 8) during catalyst activation and $\mathrm{CO}$ flushing of a used catalyst, respectively. In Figure 7, COS formation was dominant when the catalyst was not activated, decreasing to zero at fully activated state, while a small amount of COS was formed at a later reaction time. The latter must be the result of reaction of a small amount of $\mathrm{CO}$ with sulfur on the catalyst surface. The COS evọlution profile shown in Figure 8 resulted from the reaction of $\mathrm{CO}$ and residual sulfur on the surface during $2 \% \mathrm{CO} / \mathrm{He}$ scavenging of the used catalysts following a helium flush. A simple exponential decay of $\operatorname{COS}(t)$ predicted by assuming a formation rate ${ }^{r} \mathrm{COS}=k_{S}[S]_{\text {surface }}{ }^{P}$ CO fits well the experimental data.

\section{CONCLUSION}

Strong interaction of ceria and copper contributes to the catalytic activity enhancement for the $\mathrm{Cu}-\mathrm{Ce}-\mathrm{O}$ system. The copper in finely dispersed state rather than in solid solution may benefit the catalytic performance. The $\mathrm{Cu}-\mathrm{Ce}$ O composite was enriched in copper on the surface and some of the surface 
copper was converted to sulfide after use. Increasing copper content may result in high surface coverage(large copper particles) and decrease the strong interaction of ceria and copper. This may also favor the formation of undersirable by product COS. Further characterization of this catalyst system by surface analysis and the probe reaction $\left(\mathrm{CO}+\mathrm{O}_{2}\right)$ will be reported next quarter.

\section{JReference}

1 C.D.Wagner, W.M. Rigg, L.E.Davis, J.F.Moulder and G.E.

Muilenberg, Handbook of X-ray Photoelectron Spectroscopy, PerkinElmer Corporation, 1978.

2 W.Liu, M. Flytzani-Stephanopoulos and A. F. Sarofim DOE, Quarterly Technical Report No. 4, 1993

3 H.C.Yao and Y.F.Y. Yao, J. Catal., 86(1984)254-265. 
Table 1

Binding Energies of Elements in the $\mathrm{Cu}_{0.15} \mathrm{Ce}_{0.85}(\mathrm{La}) \mathrm{O}_{\mathrm{x}}$ Catalyst Determined by ESCA MULTIPLEX(mg, $300 \mathrm{~W}$ )

\begin{tabular}{llll}
\hline element & fresh(eV) & used(eV) & notea \\
\hline $\mathrm{Cu}_{2 \mathrm{p} 3 / 2}$ & 932.7 & 932.4 & $\begin{array}{l}\mathrm{Cu}, \mathrm{Cu}_{2} \mathrm{O} \\
\text { copper sulfide }\end{array}$ \\
$\mathrm{Ce} 3 \mathrm{~d} 5 / 2$ & 881.9 & 882.4 & $\mathrm{CeO}_{2}$ \\
$\mathrm{O}_{1 \mathrm{~s}}$ & 529.0 & $529.3(72 \%)$ & metal oxide $\left(\mathrm{CeO}_{2}\right)$ \\
& & $531.7(28 \%)$ & metal sulfate, carbonate \\
$\mathrm{S}_{2 \mathrm{p}}$ & - & $162.6(74 \%)$ & copper sulfide \\
& & $168.0(26 \%)$ & metal sulfate \\
\hline
\end{tabular}

a: assignment primarily based on the data in Wagner, C.D. et al.(eds.), Handbook of X-ray Photoelectron Spectroscopy ${ }^{1}$. 
Table 2

Surface Compositional Analysis of $\mathrm{Cu}_{0.15} \mathrm{Ce}_{0.85}(\mathrm{La}) \mathrm{O}_{\mathbf{X}}$ Catalyst by XPS

\begin{tabular}{lll}
\hline Atomic ratio & $\mathrm{Cu} / \mathrm{Ce}$ & $\mathrm{S} / \mathrm{Cu}$ \\
\hline bulk materiala $^{\text {fresh catalyst surface }}$ & 0.176 & 0 \\
$\begin{array}{l}\text { used catalyst } \\
\text { initial surface }\end{array}$ & 0.133 & \\
1-min Ar & \\
7-min $\mathrm{Ar}^{+}$sputtering & 0.206 & 1.59 \\
\hline
\end{tabular}

a: based on stoichiometry. 


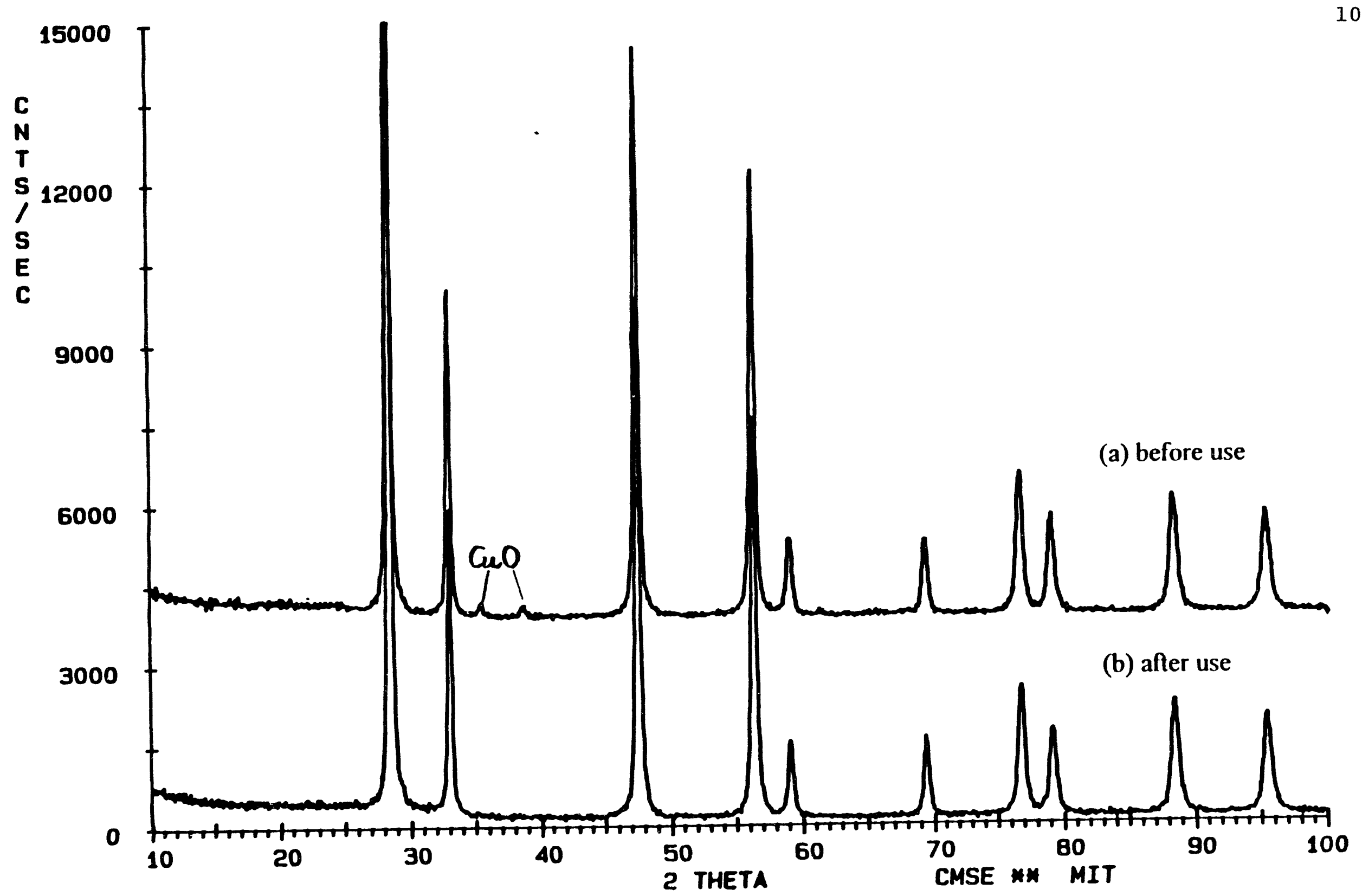

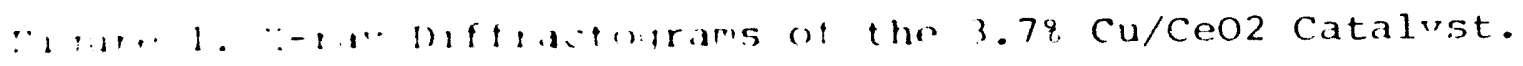




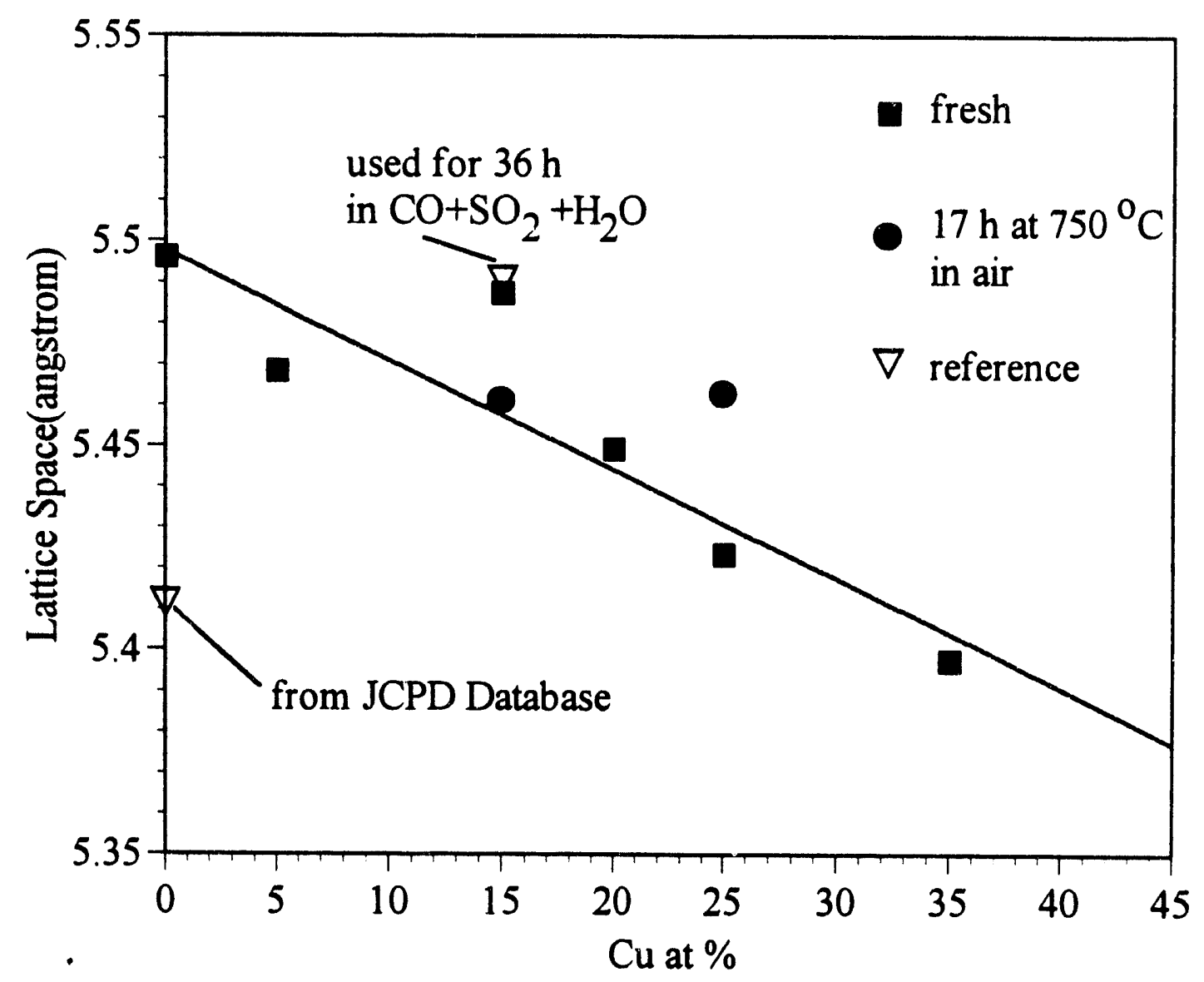

Figure 2. Variation of Lattice Parameter of $\mathrm{CeO}_{2}$ with Copper Content and Thermal Treatment 

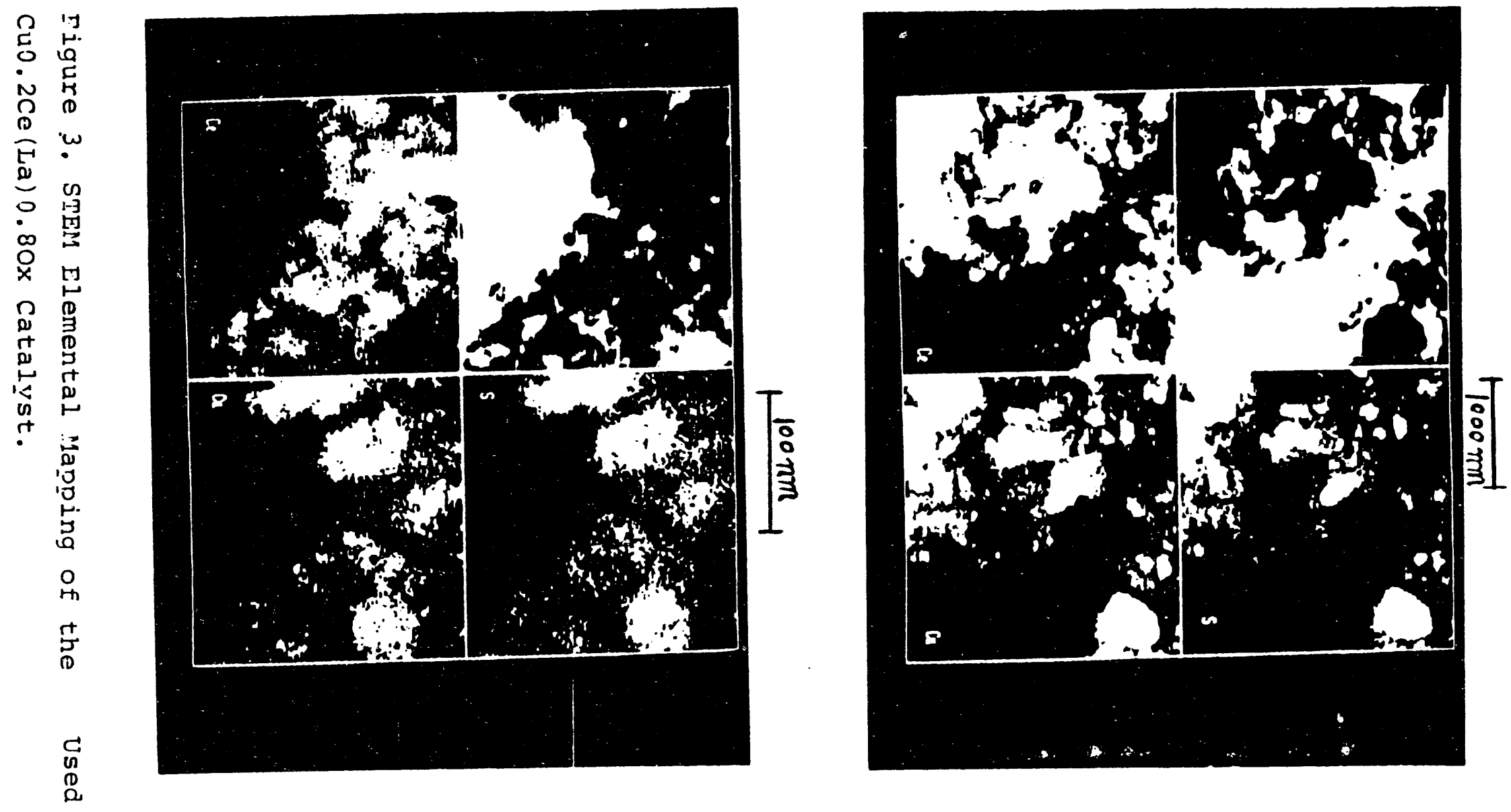

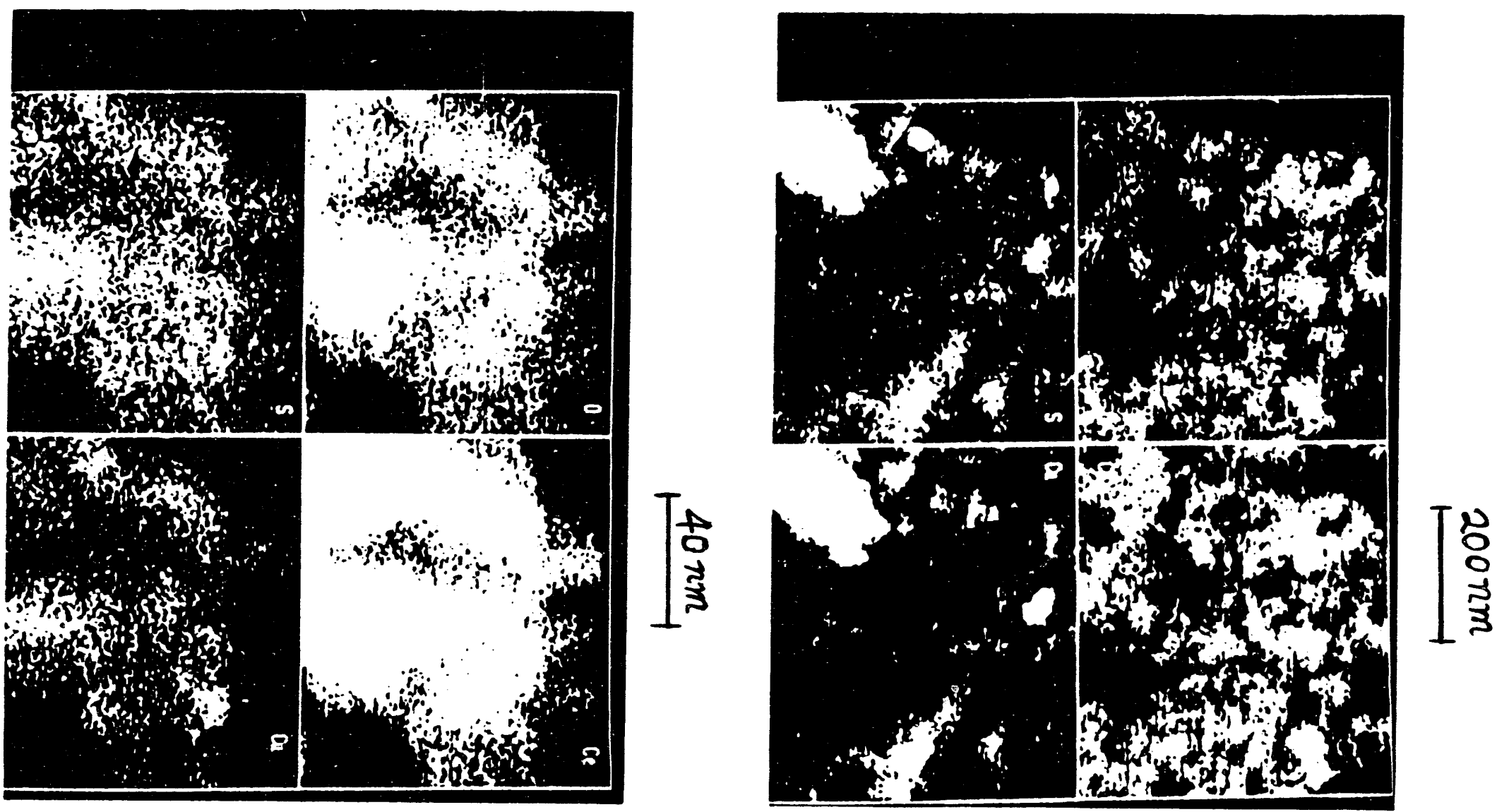

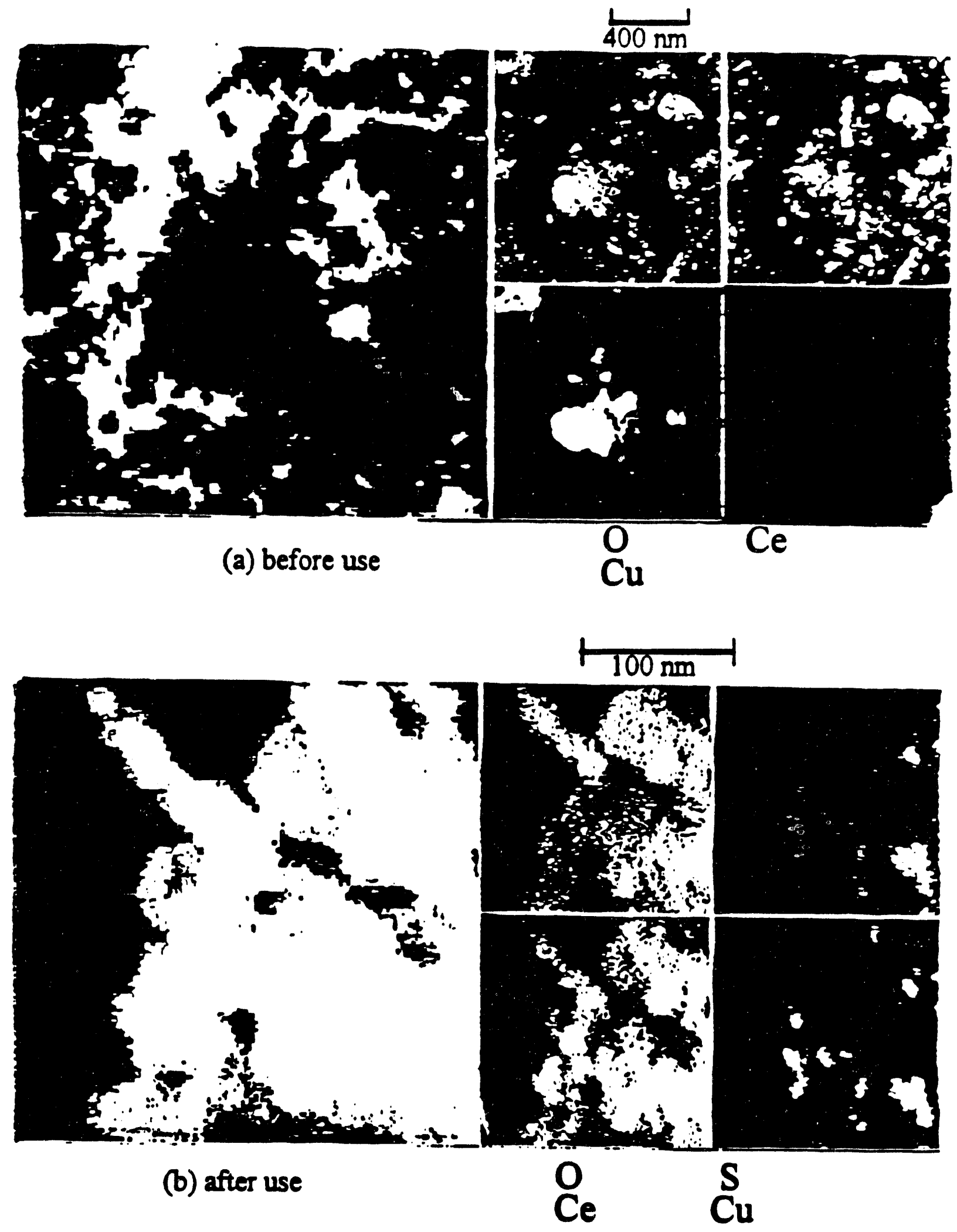

Figure 5. STEM Elemental Mapping of the $3.7 \% \mathrm{Cu} / \mathrm{CeO} 2$ Catalyst. 


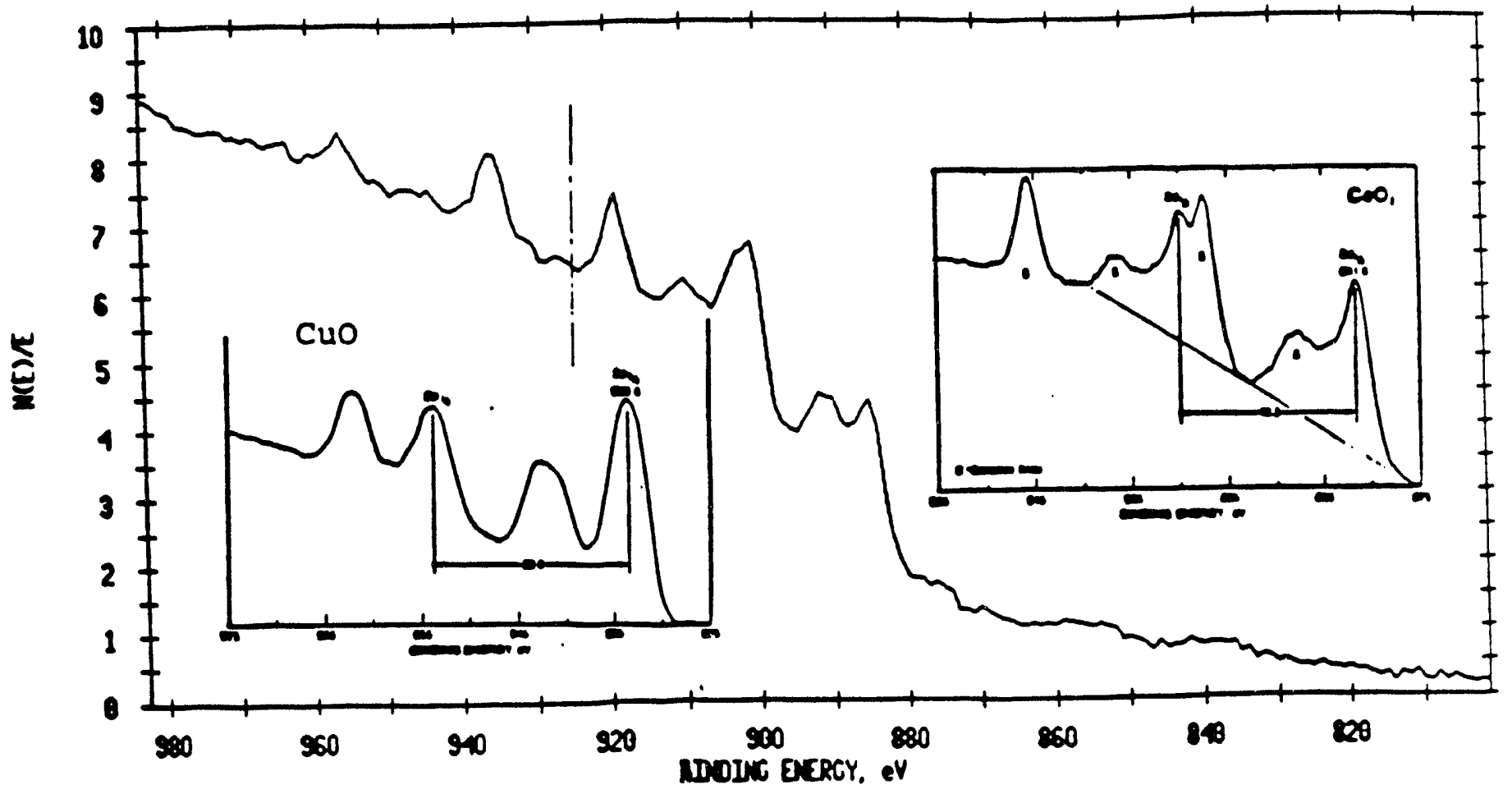

(a)

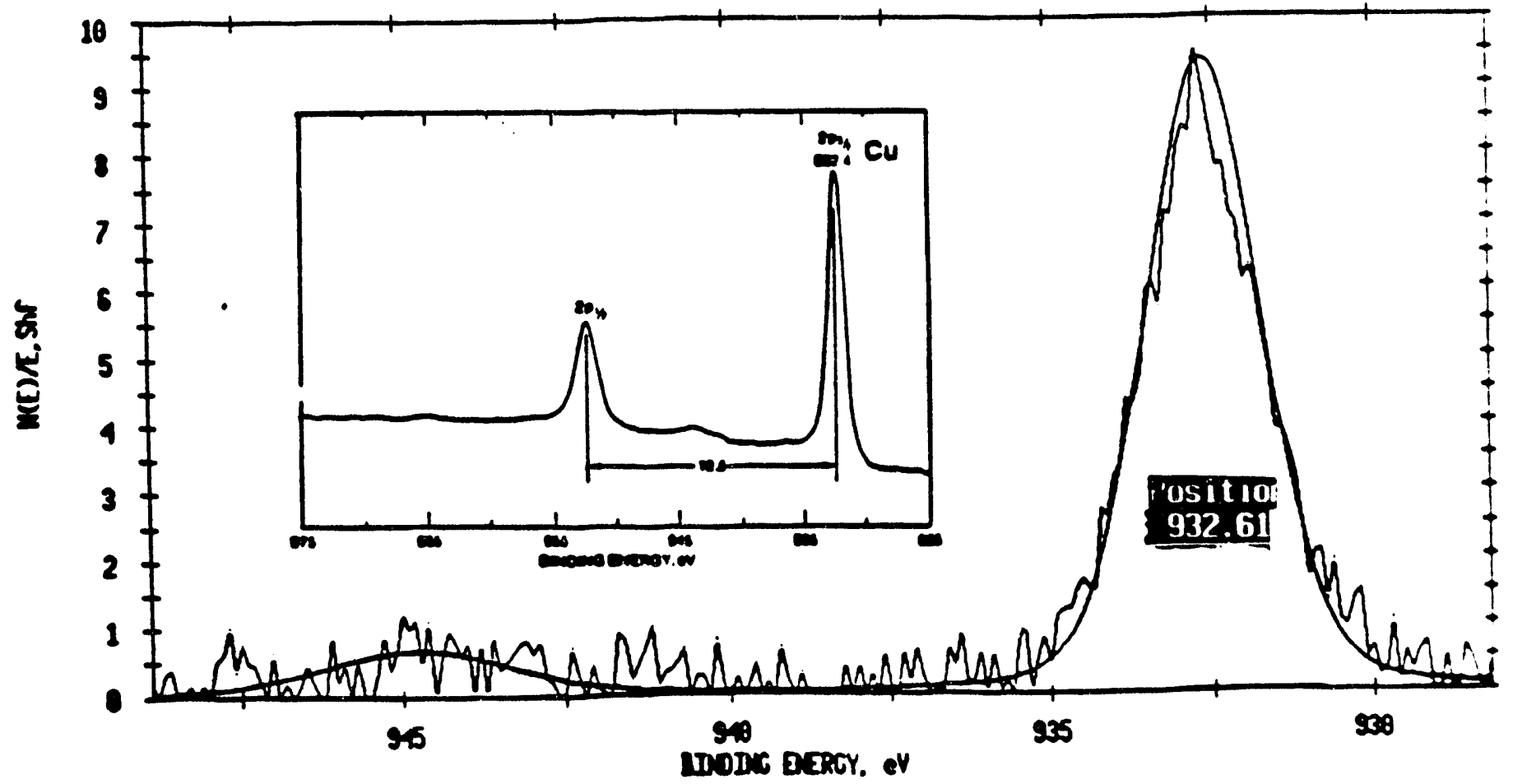

(b)

Figure 6. XPS of Fresh Cu0.15Ce(La) $0.850 x$ Catalyst(mg, $300 \mathrm{w}$ ) (a) Survev.(b) Multiolex. 


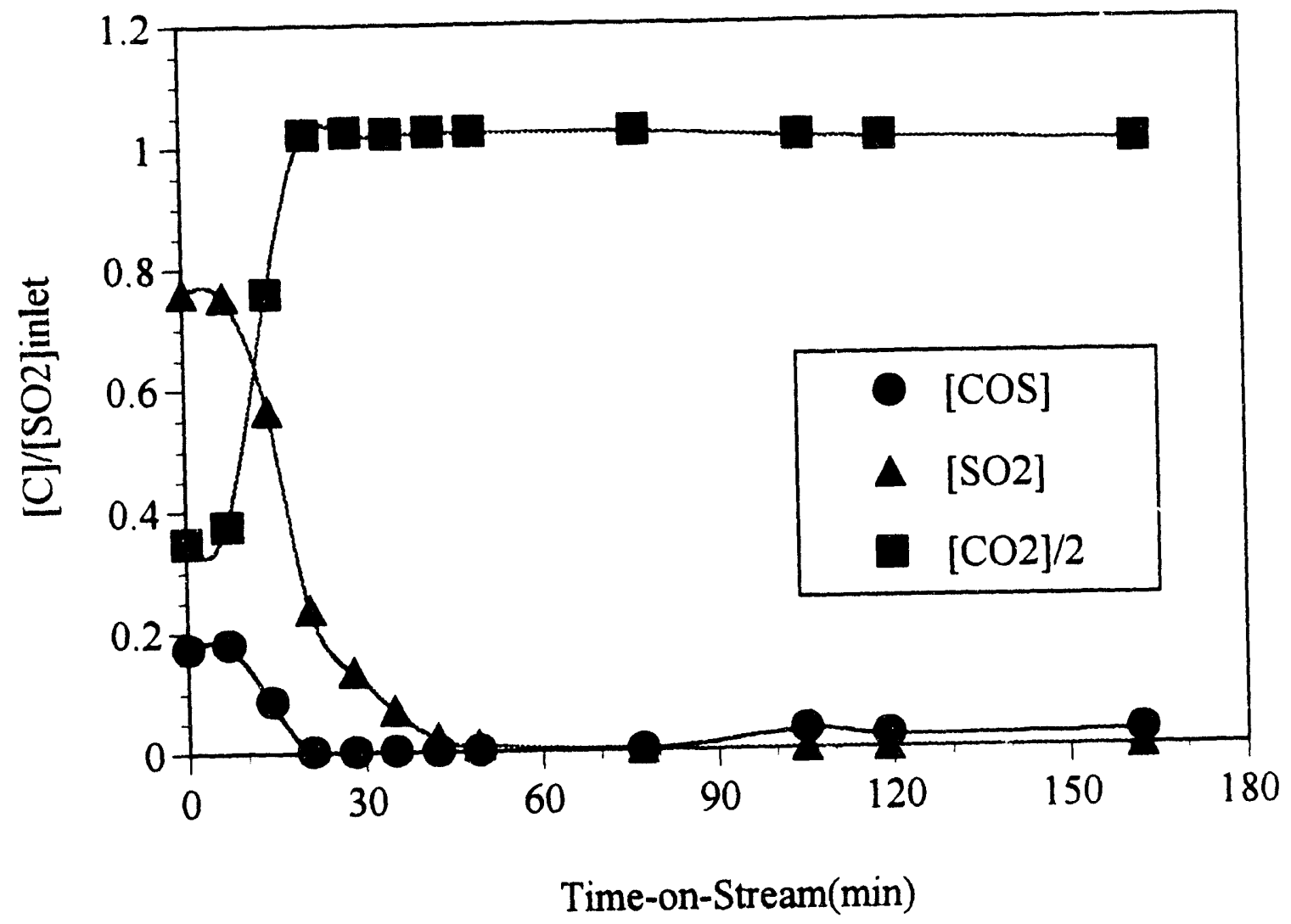

Figure 7. Activation Profile of $\mathrm{Cu}_{0.15} \mathrm{Ce}(\mathrm{La})_{0.85} \mathrm{O}_{x}$ Catalyst at $510{ }^{\circ} \mathrm{C}\left(1 \% \mathrm{SO}_{2}, 2.06 \% \mathrm{CO}\right)$. 


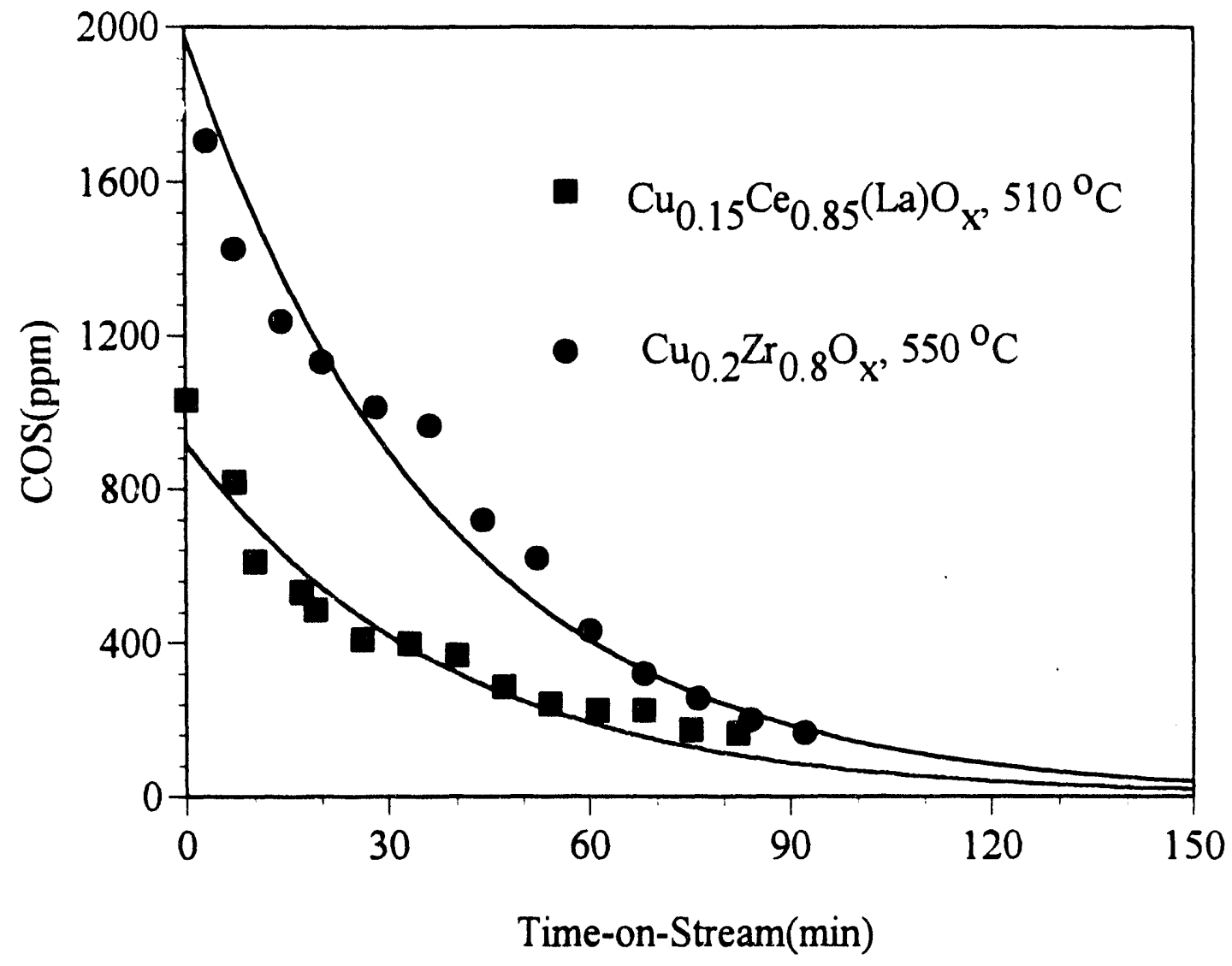

Figure 8. COS Evolution Profile During 2\% CO/He Scavenging of Spent Catalyst. 
$\Gamma$
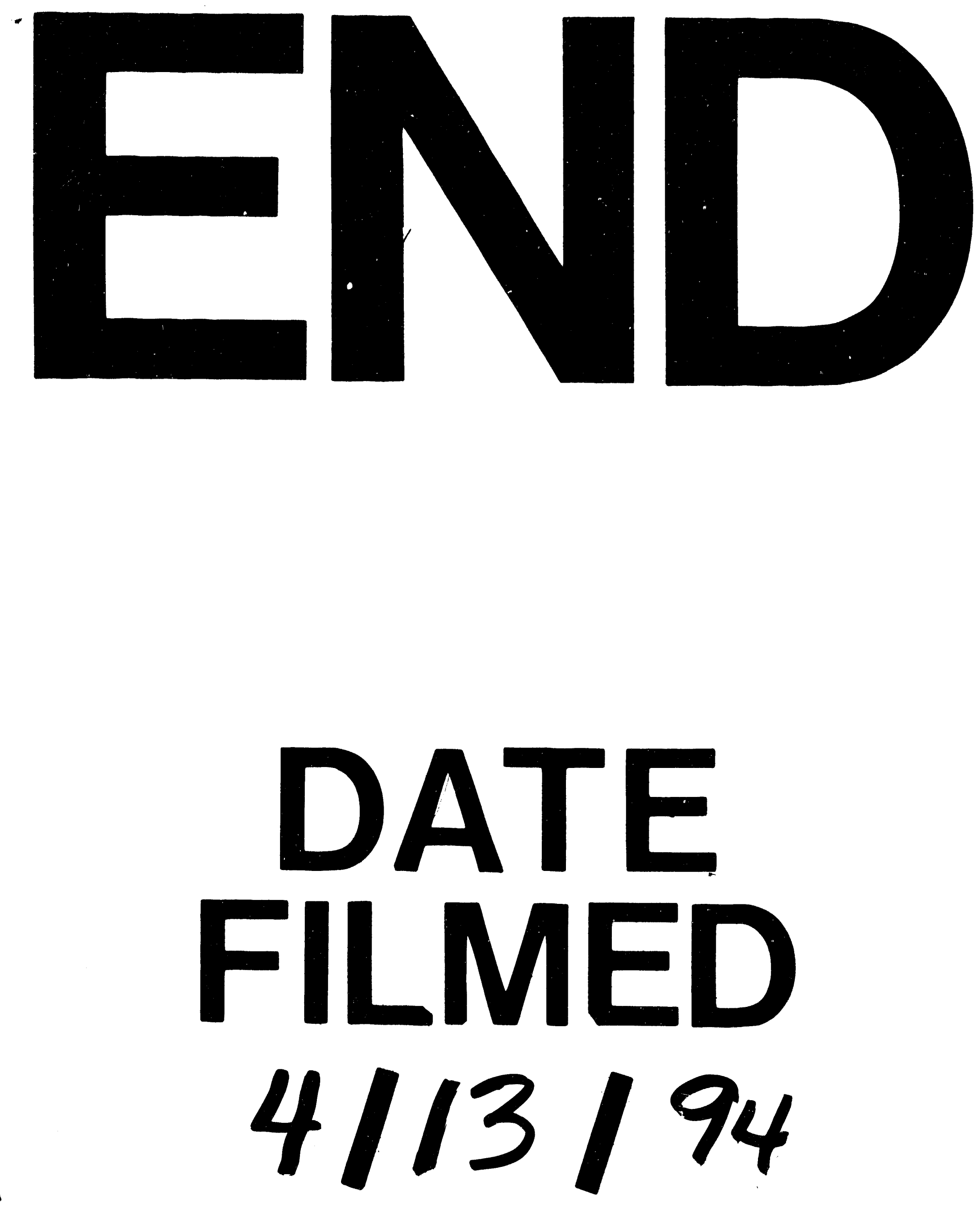
